\title{
Serum anti-AEG-1 auto-antibody is a potential novel biomarker for malignant tumors
}

\author{
XI CHEN ${ }^{*}, \mathrm{KE} \mathrm{DONG}^{*}$, MIN LONG, FANG LIN, XI WANG, JUNXIA WEI, JIHONG REN and HUIZHONG ZHANG \\ Department of Medicine Laboratory and Research Center, Tangdu Hospital, \\ Fourth Military Medical University, Xi'an, Shaanxi 710038, P.R. China
}

Received January 17, 2012; Accepted April 23, 2012

DOI: $10.3892 / \mathrm{ol} .2012 .734$

\begin{abstract}
Malignant tumors are the leading cause of mortality worldwide. The search for new biomarkers for the early diagnosis of the onset of cancer to reduce high mortality is crucial. The potential of minimal invasive testing using serum from patients renders auto-antibodies promising biomarkers for cancer diagnosis. In this study, a 181 amino acid peptide of extracellular astrocyte elevated gene-1 (AEG-1) was expressed and purified, and the peptide was used in an ELISA assay to detect anti-AEG-1 auto-antibodies (AEG-1-Abs) in 483 serum samples from different cancer patients and 230 serum samples from normal blood donors. The results showed that AEG-1-Abs at titers $\geq 1: 50$ were detected in 238 of $483(49 \%)$ cancer patients, and the positive antibody responses in different cancer patients were as follows: 44 of $98(45 \%)$ in breast cancer patients, 48 of $96(50 \%)$ in hepatic carcinoma patients, 43 of $88(49 \%)$ in rectal cancer patients, 51 of $113(45 \%)$ in lung cancer patients, and 52 of $88(59 \%)$ in gastric cancer patients. These results were compared with 0 of $230(0 \%)$ in normal individuals. Moreover, AEG-1-Abs at titers $\geq 1: 50$ were also detected in 24 of $94(26 \%)$ cancer patients in TNM stages I and II, and the positive rates of AEG-1-Abs decreased with age. These results suggest that the AEG-1-Ab response acts as a diagnostic biomarker for cancer patients with AEG-1-positive expression, and may also prove to be a possible inducer, with substantial immunity against AEG-1 by immunization boosting with AEG-1 vaccines.
\end{abstract}

\section{Introduction}

Malignant tumors, which have become a prominent health care issue, are the most serious current threat to human life and

Correspondence to: Dr Huizhong Zhang, Department of Medicine Laboratory and Research Center, Tangdu Hospital, Fourth Military Medical University, Xinsi Road, Xi'an, Shaanxi 710038, P.R. China E-mail: zhz0105@yahoo.com.cn

\section{"Contributed equally}

Key words: astrocyte elevated gene-1, anti-AEG-1 auto-antibody, serum, tumor biomarker, cancer health of all major diseases. According to the World Health Organization, 7.6 million individuals worldwide succumbed to malignant tumors (approximately 13\% of all mortalities) in 2008. Mortalities from cancer worldwide are likely to continue to increase to over 11 million in 2030 (1). Thus, malignant tumors have become a serious threat and the number one cause of mortality. However, cancer mortality may be reduced if early detection and treament occurs, and the real challenge is to develop novel markers that are suitable for early diagnosis and prophylactic screening.

Auto-antibodies are present in the blood of patients who are affected by malignant tumors $(2,3)$. Numerous antibodies against autologous cell proteins may be detected in the sera of patients with various types of cancer, which may have been present in the patient in the early stages of cancer. These antibodies are directed against a group of autologous cellular antigens, generally known as tumor-associated antigens (TAAs) (4-6). Auto-antibodies circulate for a longer time than other polypeptides, since they are stable in the serum and are often produced in large amounts. Therefore, serum profiling of circulating auto-antibodies is considered an attractive method in the diagnosis of cancer at early stages. Several markers, such as Her2, BPAG1 and GRP78, have been detected and proposed for immunotherapeutic approaches (7-9), such as high-titer HER-2/neu protein-specific antibody, which was detected in patients with early stage breast cancer (7). The levels of antiBPAG1 auto-antibodies were significantly higher in the sera of melanoma patients than in those of the healthy volunteers, and anti-BPAG1 auto-antibodies were detected in melanoma patients at the early and advanced stages of disease (8). However, these particular markers are only suitable for patients with specific cancers, but not for all types of cancer.

Astrocyte elevated gene-1 (AEG-1, also known as MTDH and Lyric), a novel gene that was cloned in 2002 (10), is a transmembrane protein and an important genetic determinant involved in the regulation of multiple events in tumorigenesis. Expression analysis has revealed that AEG-1 is overexpressed in a number of types of cancer including breast, liver, esophageal and prostate cancer, as well as in melanoma and malignant glioma in comparison to their normal counterparts (11-16). AEG-1 has emerged as a potentially crucial mediator in several aspects of tumor progression in recent years $(17,18)$. Gain-of-function and loss-of-function studies demonstrate a significant role of AEG-1 in the process of tumorigenesis. 
Overexpression of AEG-1 is crucial in the maintenance of the malignant phenotype in human malignancies $(13,17,19-22)$. AEG-1 promoted tumorigenesis by modulating multiple signal transduction pathways and altering global gene expression changes. The mechanism of AEG-1 in the development and prognosis of tumors is not fully elucidated.

Therefore, this study was designed to evaluate the presence of anti-AEG-1 auto-antibody immunity in a broader spectrum of tumors, such as hepatic carcinoma, and breast, rectal, lung and gastric cancer.

\section{Materials and methods}

Patient information and serum specimens. Following informed consent, serum samples were obtained at the time of initial diagnosis from 98 patients with breast cancer, 96 with hepatic carcinoma, 88 with rectal cancer, 113 with lung cancer, and 88 with gastric cancer (260 females and 223 males; median age 53 years; range 21-81), at the Tangdu Hospital of the Fourth Military Medical University between 2009 and 2011. None of the cancer patients in this study had received preoperative radiation therapy or chemotherapy. For the use of these clinical materials for research purposes, prior consent from patients and approval from the Institute Research Medical Ethics Committee of Tangdu Hospital were obtained. Sera were stored in aliquots at $-80^{\circ} \mathrm{C}$ until use.

Normal blood donors. Control serum samples were obtained from normal donors who contributed blood at the Tangdu Hospital of Fourth Military Medical University. Samples from 115 females and 115 males were stored at $-80^{\circ} \mathrm{C}$. The age range of the control group was between 20 and 70 years old.

Cloning of the AEG-1 cDNA and construction of the prokaryotic expression vector. To construct the prokaryotic expression vector, a 543 bp AEG-1 gene fragment (from 1140 to $1682 \mathrm{bp}$, part of the extracellular domain) that encodes the lung-homing domain (amino acid 381-443) (23) was amplified using the PCR method and the human lung cancer cell line A549 (purchased from ATCC, Manassas, VA, USA) cDNA as a template. The primers which introduced $N c o$ I and $\mathrm{SacI}$ restriction enzyme sites were as follows: sense: 5'-GCCCATGGTAGTTTCTTCAGGATTG-3' (1140-1154); and antisense: 5'-CCGGAGCTCGTTATCTTCACCTTGC-3' (1682-1696). The PCR products were excised from agarose gel and isolated using the gel extraction kit (Invitrogen, Branchburg, NJ, USA). The purified AEG-1 fragment was inserted into a pGSTag expression vector. The recombinant vector was designated as pGSTag-AEG-1-lung-homing.

AEG-1-lung-homing domain peptide expression and purification. BL21 (DE3) pLysS codon + E.coli were transformed with a pGSTag-AEG-1-lung-homing recombinant vector, and the transformants were selected on LB plates containing ampicillin. Colonies were grown overnight at $37^{\circ} \mathrm{C}$ in $\mathrm{LB}$ broth supplemented with $100 \mathrm{mg} / \mathrm{ml}$ ampicillin. The overnight culture was diluted 25 -fold with fresh LB medium and cultured at $37^{\circ} \mathrm{C}$ until an optical density (OD) at $600 \mathrm{~nm}$ of 0.6 was achieved. The protein expression was induced by the addition of $1 \mathrm{mM}$ IPTG (Sigma) and was incubated at $37^{\circ} \mathrm{C}$ for $4 \mathrm{~h}$. Bacteria were collected by centrifugation and lysed by sonication. The suspensions were collected by centrifugation at $12,000 \mathrm{rpm}$ for $20 \mathrm{~min}$ at $4^{\circ} \mathrm{C}$. To purify GST-AEG-1-lunghoming fusion protein, 50\% slurry of glutathione sepharose 4B beads was added and incubated for $30 \mathrm{~min}$ at room temperature with gentle agitation (GE Healthcare Bio-Sciences AB, Sweden), and then centrifuged at $500 \mathrm{~g}$ for $5 \mathrm{~min}$ to pellet the beads. To remove the unbound proteins after washing, $0.5 \mathrm{ml}$ glutathione elution buffer per $\mathrm{ml}$ bed volume was added, incubated at room temperature for $10 \mathrm{~min}$, and centrifuged at $500 \mathrm{~g}$ for $5 \mathrm{~min}$ to collect the supernatant. Fusion protein purity was checked by $12 \%$ SDS-PAGE and further confirmed by western blot analysis using anti-AEG-1 antibody. Protein concentrations were determined by densitometric analysis using bovine serum albumin (BSA) as the standard (Bio-Rad, Hercules, CA, USA).

Enzyme-linked immunosorbent assay (ELISA) for the detection of anti-AEG-1 auto-antibody in the sera of different cancer patients. Anti-AEG-1 auto-antibody in sera from cancer patients was detected by analyzing the experimental sera response to purified GST-AEG-1-lung-homing peptide by ELISA as described previously (24). In these analyses, plates were incubated with $150 \mu \mathrm{l} /$ well purified GST-AEG-1lung-homing peptide at a concentration of $4 \mu \mathrm{g} / \mathrm{ml}$ overnight at $4^{\circ} \mathrm{C}$. Plates incubated with $150 \mu \mathrm{l} /$ well purified GST protein were used as a negative control. Following incubation, the wells were blocked with $1 \%$ BSA $200 \mu \mathrm{l} /$ well for $2 \mathrm{~h}$ at $37^{\circ} \mathrm{C}$. The plates were washed with PBST ( $0.5 \%$ Tween), and $50 \mu 1$ human sera from various cancer patients (at dilutions of 1:1, 1:5, 1:10, 1:25, 1:50, 1:100 and 1:1,000) were added per well and incubated for $2 \mathrm{~h}$ at $37^{\circ} \mathrm{C}$. After washing, peroxidase-conjugated goat anti-human IgG (HRP) was added to the wells at a 1:5,000 dilution in PBST and incubated for $1 \mathrm{~h}$ at $37^{\circ} \mathrm{C}$. Following the final wash, OPD developing reagent was added. The reaction was terminated with $2 \mathrm{M}$ sulfuric acid, and the OD was read at $490 \mathrm{~nm}$.

Statistical analysis. Each experiment was repeated 3 times, and all data were indicated as the means \pm standard deviation $( \pm \mathrm{s})$. Student's t-test was utilized to evaluate the difference between treated and control groups $(\mathrm{p}<0.05)$.

\section{Results}

Design of expression vectors, and expression and purification of fusion proteins. To express the lung-homing domain of extracellular AEG-1, the prokaryotic expression vector of pGSTag-AEG-1-lung-homing was constructed. The GST-AEG-1-lung-homing fusion peptide was expressed from a bacterial source, and it was purified by glutathione sepharose 4B beads (Fig. 1). Analysis of expression products by western blot analysis with anti-AEG-1 antibody revealed that the recombinant proteins exhibited the expected size of $49 \mathrm{kDa}$ and were highly enriched under native conditions with reproducibly high levels of expression ( $7.5 \mathrm{mg} / \mathrm{l}$ culture).

ELISA detection of anti-AEG-1 auto-antibodies in sera from various cancer patients. Patients with different types of cancer had antibodies directed against the AEG-1 oncogenic 
A

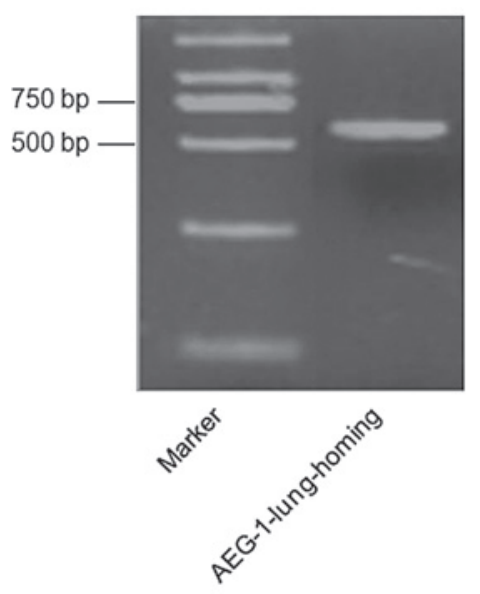

B

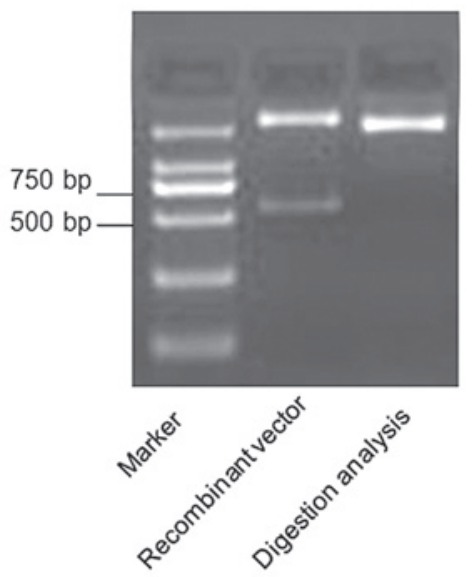

C

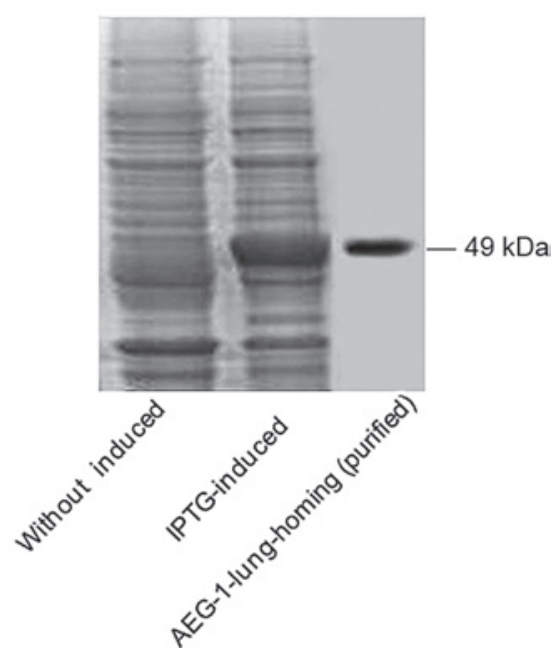

Figure 1. Cloning and expression of AEG-1-lung-homing. (A) The PCR production of DNA-coded AEG-1-lung-homing gene (543 bp). (B) Digestion analysis of pGSTag-AEG-1-lung-homing vector by NcoI and SacI. (C) SDS-PAGE analysis of the GST-AEG-1-lung-homing fusion protein induced by IPTG and the purified fusion protein, i.e., the GST-AEG-1-lung-homing.

Table I. Positive rates of serum anti-AEG-1 auto-antibody in different types of cancer patients and normal individuals.

\begin{tabular}{lcccc}
\hline Sample & $\begin{array}{c}\text { Total } \\
\text { sample } \\
\text { number }\end{array}$ & $\begin{array}{c}\text { AEG-1 } \\
\text { auto-antibody } \\
\text { positive number }\end{array}$ & N (\%) & P-value \\
\hline Breast cancer & 98 & 44 & 45 & $<0.01$ \\
Hepatic & 96 & 48 & 50 & $<0.01$ \\
carcinoma & & 43 & 49 & $<0.01$ \\
Retal cancer & 88 & 51 & 45 & $<0.01$ \\
Lung cancer & 113 & 52 & 59 & $<0.01$ \\
Gastric cancer & 88 & 238 & 49 & $<0.01$ \\
Total cancer & 483 & 0 & 0 & \\
Normal & 230 & & & \\
\hline
\end{tabular}

${ }^{a}$ Compared with normal sample. AEG-1, astrocyte elevated gene-1.

protein. Sera were obtained from various cancer patients, including 98 with breast cancer, 96 with hepatic carcinoma, 88 with rectal cancer, 113 with lung cancer and 88 with gastric cancer at the time of initial diagnosis and the samples were analyzed for the presence of antibodies directed against the AEG-1 oncoprotein. Antibodies at titers $\geq 1: 50$ were detected in 238 of 483 (49\%) cancer patients. Antibodies detected in patients with different types of cancer were as follows: 44 of $98(45 \%)$ in breast cancer patients, 48 of $96(50 \%)$ in hepatic carcinoma patients, 51 of $113(45 \%)$ in lung cancer patients, 43 of $88(49 \%)$ in rectal cancer patients, and 52 of $88(59 \%)$ in gastric cancer patients, compared with 0 of $230(0 \%)$ normal individuals (Table I, $\mathrm{p}<0.01$ ). These results demonstrated that AEG-1-Abs were present in a broad range of malignant tumors.

Association between anti-AEG-1 auto-antibody levels and the clinicopathological characteristics of cancer patients.
Table II. Association between the clinicopathological characteristics of cancer patients and the presence of anti-AEG-1 auto-antibodies.

\begin{tabular}{lcccc}
\hline Sample & $\begin{array}{c}\text { Total } \\
\text { sample } \\
\text { number }\end{array}$ & $\begin{array}{c}\text { Anti-AEG-1 } \\
\text { auto-antibody } \\
\text { positive number }\end{array}$ & N (\%) & P-value \\
\hline Gender & & & & \\
Male & 223 & 107 & 48 & 0.599 \\
Female & 260 & 131 & 50 & \\
Metastasis & & & & 0.872 \\
Yes & 98 & 49 & 50 & \\
No & 385 & 189 & 49 & \\
Age (years) & & & & $<0.01$ \\
$<60$ & 287 & 168 & 59 & \\
$\geq 60$ & 196 & 70 & 36 & \\
\hline
\end{tabular}

AEG-1, astrocyte elevated gene-1.

AEG-1-Abs at titer $\geq 1: 50$ were detected in 238 of 483 (49\%) cancer patients (260 females and 223 males). The positive rate of AEG-1-Abs in female patients was the same as that in male patients. No significant difference was observed between the patients with or without metastasis $(p>0.05)$. However, AEG-1-Abs at titer $\geq 1: 50$ were detected in 168 of $287(59 \%)$ of patients $<60$ years old, but it was only detected in 70 of 196 $(36 \%)$ of patients who were $>60$ years old (Table II, $\mathrm{P}<0.01$ ). These results demonstrated that the positive rate of AEG-1-Abs decreases with age.

Anti-AEG-1 auto-antibody levels in different clinical TNM stages of patients. The positive rate of antibodies to AEG-1 was different in the various TNM stages of patients. In stage I 
Table III. Antibodies to AEG-1 detected at the time of diagnosis in different stage patients.

\begin{tabular}{|c|c|c|c|}
\hline Sample & $\begin{array}{c}\text { AEG-1-Abs positive } \\
\text { case } \mathrm{n}(\%) \text { in stage I and II }\end{array}$ & $\begin{array}{c}\text { AEG-1-Abs positive } \\
\text { case } \mathrm{n}(\%) \text { in stage III and IV }\end{array}$ & $\mathrm{P}$-value \\
\hline Breast cancer & $9(30)$ & $35(51)$ & 0.049 \\
\hline Hepatic carcinoma & $8(26)$ & $40(62)$ & 0.001 \\
\hline Rectal cancer & $6(30)$ & $37(54)$ & 0.055 \\
\hline Lung cancer & $8(35)$ & $43(48)$ & 0.264 \\
\hline Gastric cancer & $9(39)$ & $43(64)$ & 0.023 \\
\hline Total cancer & $40(31)$ & $198(56)$ & $<0.01$ \\
\hline
\end{tabular}

AEG-1-Abs, anti-AEG-1 auto-antibodies.

and II cancer patients, antibodies were detected in 40 of 127 $(31 \%)$ in all cancer patients at titers $\geq 1: 50$ or greater, 9 of 30 $(30 \%)$ in breast cancer patients, 8 of $31(26 \%)$ in hepatic carcinoma patients, 6 of $20(30 \%)$ in lung cancer patients, 8 of 23 $(35 \%)$ in rectal cancer patients, and 9 of $23(39 \%)$ in gastric cancer patients. However, in stage III and IV patients, there were 198 of $356(56 \%)$ in all cancer patients, and 35 of $68(51 \%)$ in breast cancer patients, 40 of $65(62 \%)$ in hepatic carcinoma patients, 37 of 68 (54\%) in lung cancer patients, 43 of $90(48 \%)$ in rectal cancer patients, and 43 of $65(64 \%)$ in gastric cancer patients (Table III, $\mathrm{P}<0.01$ ). Our results revealed that the levels of AEG-1-Abs had a significant correlation with the stage of patients, and may be used as a novel marker of the progression of cancer patients.

\section{Discussion}

Investigators have previously demonstrated that the sera of cancer patients contained antibodies that were capable of reacting with TAAs $(15,16)$. The types of TAAs that induce these auto-antibody responses are varied and include the tumor-suppressor p53 $(25,26)$ and oncogene products, such as HER-2/neu proteins (20). Human AEG-1 mRNA encodes a single-pass transmembrane oncoprotein with a molecular mass of $64 \mathrm{kDa}(2,9)$. Studies on AEG-1 from our laboratory and others (11-16) have shown that AEG-1 was overexpressed in almost all types of malignant tumors, and expression analysis of cancer samples and normal samples has established that AEG-1 acts a potential TAA. Thus, we presumed that this oncoprotein may induce the auto-antibody response in the serum of cancer patients, and these AEG-1-Abs may be potential markers for the diagnosis and prognostic evaluation of cancer patients.

In this study, the GST-AEG-1-lung-homing fusion protein (amino acid 271-451 NP_848927) which contained the lung-homing domain of AEG-1 was initally expressed and purified. Using the ELISA assay, peptides were used as a capture agent to detect AEG-1 auto-antibody responses in sera from 483 patients suffering from different types of cancer, and sera from 230 normal blood donors were used as controls. This is the first report regarding the detection of AEG-1-Abs in cancer patients. Our results demonstrate that antibody reactivity correlates with the presence of cancer. Antibodies at titers $\geq 1: 50$ or greater were detected in 238 of $483(49 \%)$ cancer patients, as well as in hepatic carcinoma (50\%), lung (45\%), breast $(45 \%)$, gastric $(59 \%)$ and rectal $(49 \%)$ cancer patients. Furthermore, the positive rates of AEG-1-Abs decreased with age (Table I, $\mathrm{P}<0.01$ ).

The identification of TAAs that elicit an immune response is important for clinical applications both for the early diagnosis of tumors and for the immunotherapy strategy design. In this study, AEG-1-Abs was also detected in some patients with early-stage cancer. In stage I and II cancer patients, AEG-1-Abs were detected in 40 of 127 (31\%) cases at titers $\geq 1: 50$ including 9 of $30(30 \%)$ breast cancer patients, 8 of $31(26 \%)$ hepatic carcinoma patients, 6 of $20(30 \%)$ lung cancer patients, 8 of 23 (35\%) rectal cancer patients, and 9 of $23(39 \%)$ gastric cancer patients. These results demonstrated that the potential utility of auto-antibody against AEG-1 could be used as an early diagnostic biomarker for a broad spectrum of cancer patients.

The identification of tumor antigens is also important for clinical therapy, such as cancer vaccines. Many tumorassociated antigens are excellent targets for immunotherapy and vaccine design. Although there are certain limitations to vaccine therapy, including the short half-life of infused antibodies, the generation of immunity to the antibody construct and the inability of antibodies to penetrate solid tumors, our results provided evidence that AEG-1-Abs may be detected in the sera of a broad range of cancer patients, and suggested that it is possible to induce substantial immunity against AEG-1 by immunization boosting with AEG-1 vaccines, which are paving the way for further investigation of AEG-1-based immunotherapy approaches.

To the best of our knowledge, this report is the first to show that AEG-1-Abs, as a novel marker of malignant tumors, may be detected in the sera of different cancer patients. However, more studies are required to develop this marker into a more sophisticated method that can be used clinically.

\section{Acknowledgements}

We thank the Department of Clinical Laboratory of the Tangdu Hospital of Fourth Military Medical University for samples used in this study. This study was supported by a grant from the National Natural Science Foundation of China (no. 81001195). 


\section{References}

1. Ferlay J, Shin HR, Bray F, Forman D, Mathers C and Parkin DM: GLOBOCAN 2008 v1.2, Cancer Incidence and Mortality Worldwide: IARC CancerBase No. 10. Lyon, France. http:// globocan.iarc.fr.

2. Caron M, Choquet-Kastylevsky G and Joubert-Caron R: Cancer immunomics using autoantibody signatures for biomarker discovery. Mol Cell Proteomics 6: 1115-1122, 2007.

3. Desmetz C, Cortijo C, Mange A and Solassol J: Humoral response to cancer as a tool for biomarker discovery. Proteomics 72 : 982-988, 2009.

4. Zhang JY, Megliorino R, Peng XX, Tan EM, Chen Y and Chan EKL: Antibody detection using tumor-associated antigen mini-array in immunodiagnosing human hepatocellular carcinoma. Hepatology 46: 107-114, 2007.

5. Tan EM and Zhang JY: Autoantibodies to tumor-associated antigens: reporters from the immune system. Immunol Rev 222 328-340, 2008.

6. Lu HL, Goodell V and Disis ML: Humoral immunity directed against tumor-associated antigens as potential biomarkers for the early diagnosis of cancer. J Proteome Res 7: 1388-1394, 2008.

7. Disis ML, Pupa SM, Gralow JR, Dittadi R, Menard S and Cheever MA: High-titer HER-2/neu protein-specific antibody can be detected in patients with early-stage breast cancer. J Clin Oncol 15: 3363-3367, 1997.

8. Shimbo T, Tanemura T, Yamazaki T, Tamai K, Katayama I and Kaneda Y: Serum anti-BPAG1 auto-antibody is a novel marker for human melanoma. PLoS One 5: e10566-e10573, 2010.

9. Defresne F, Bouzin C, Guilbaud C, et al: Differential influence of anticancer treatments and angiogenesis on the seric titer of autoantibody used as tumor and metastasis biomarker. Neoplasia 12 $562-570,2010$

10. Su ZZ, Kang DC, Chen Y, et al: Identification and cloning of human astrocyte genes displaying elevated expression after infection with HIV-1 or exposure to HIV-1 envelope glycoprotein by rapid subtraction hybridization. Oncogene 21: 3592-3602, 2002.

11. Kang DC, Su ZZ, Sarkar D, et al: Cloning and characterization of HIV-1-inducible astrocyte elevated gene-1, AEG-1. Gene 353: $8-15,2005$

12. Yoo BK, Emdad L, Su ZZ, et al: Astrocyte elevated gene-1 regulates hepatocellular carcinoma development and progression. J Clin Invest 119: 465-477, 2009.
13. Hu GH, Chong RA, Yang QF, et al: MTDH activation by $8 \mathrm{q} 22$ genomic gain promotes chemoresistance and metastasis of poorprognosis breast cancer. Cancer Cell 15: 9-20, 2009.

14. Kikuno N, Shiina H, Urakami S, et al: Knockdown of astrocyteelevated gene-1 inhibits prostate cancer progression through upregulation of FOXO3a activity. Oncogene 26: 7647-7655, 2007.

15. Yu CP, Chen K, Zheng HQ, et al: Overexpression of astrocyte elevated gene-1 (AEG-1) is associated with esophageal squamous cell carcinoma (ESCC) progression and pathogenesis. Carcinogenesis 30: 894-901, 2009.

16. Lee SG, Jeon HY, Su ZZ, et al: Astrocyte elevated gene-1 contributes to the pathogenesis of neuroblastoma. Oncogene 28: 2476-2484, 2009.

17. Emdad L, Sarkar D, Su ZZ, et al: Astrocyte elevated gene-1: recent insights into a novel gene involved in tumor progression, metastasis and neurodegeneration. Pharmacol Therapeut 114: 155-170, 2007.

18. Lawrence $\mathrm{N}$ and Chin KL: The metastasis problem gets stickier. Cancer Cell 15: 1-2, 2009.

19. Sarkar D, Park ES, Emdad L, Lee SG, Su ZZ and Fisher PB: Molecular basis of nuclear factor- $\kappa \mathrm{B}$ activation by astrocyte elevated gene-1. Cancer Res 68: 1478-1484, 2008.

20. Emdad L, Sarkar D, Su ZZ, et al: Activation of the nuclear factor $\kappa \mathrm{B}$ pathway by astrocyte elevated gene-1: implications for tumor progression and metastasis. Cancer Res 66: 1509-1516, 2006.

21. Emdad L, Lee SG, Su ZZ, et al: Astrocyte elevated gene-1 (AEG-1) functions as an oncogene and regulates angiogenesis. Proc Natl Acad Sci USA 15: 21300-21305, 2009.

22. Khuda II, Koide N, Noman ASM, et al: Astrocyte elevated gene-1 (AEG-1) is induced by lipopolysaccharide as toll-like receptor 4 (TLR4) ligand and regulates TLR4 signaling. Immunol 128: e700-e706, 2009.

23. Brown DM and Ruoslahti E: Metadherin, a cell surface protein in breast tumors that mediates lung metastasis. Cancer Cell 5: 365-374, 2004.

24. Dong J, Zeng BH, Xu LH, et al: Anti-CDC25B auto antibody predicts poor prognosis in patients with advanced esophageal squamous cell carcinoma. J Transl Med 8: 81-88, 2010.

25. Soussi T: $p 53$ antibodies in the sera of patients with various types of cancer. Cancer Res 60: 1777-1788, 2000.

26. Crawford LV, Pim DC and Bulbrook RD: Detection of antibodies against the cellular protein $\mathrm{p} 53$ in sera from patients with breast cancer. Int J Cancer 30: 403-408, 1982. 